\title{
HIV-associated neurocognitive disorders at Moi teaching and referral hospital, Eldoret, Kenya
}

\author{
Amina Ali Mohamed ${ }^{1 *}$ (D) Chrispine Oduor ${ }^{1}$ and Daniel Kinyanjui ${ }^{2}$
}

\begin{abstract}
Background: Human Immunodeficiency Virus (HIV) infection causes a myriad of neurological complications including cognitive deficits referred to as HIV-Associated Neurocognitive Disorders (HAND). With the introduction of combination antiretroviral therapy, there has been an epidemiological shift in cognitive disorders with a decline in the more severe HIV-Associated Dementia (HAD) to an increase in the less severe HAND: Asymptomatic Neurocognitive Impairment (ANI) and HIV-associated Mild Neurocognitive Disorder (MND). Central Nervous System (CNS) involvement in HIV interferes with cognitively demanding activities of daily living and hence a worse quality of life. Early diagnosis is delayed until symptoms are overt.

Methods: We conducted a cross sectional analytical study of HIV infected persons on antiretroviral therapy attending HIV clinic. A systematic random sampling was done to select 360 patients. An interviewer administered structured questionnaire was used to collect socio-demographic data while the CD4 count and viral load were retrieved from the Academic Model Providing Access to Healthcare (AMPATH) database. Pearson's Chi Square test was used to compare proportions while independent sample t- test was used to compare continuous variables between the patients diagnosed with HAND and those without HAND. Logistic regression model was used to assess the factors associated with HAND.
\end{abstract}

Results: The mean age of the study participants was 40.2 years. The overall prevalence of HAND was (81.1\%) $N=$ 292. Mild HAND (ANI and MND) was present (78.6\%) $N=283$, Severe HAND (HAD) (2.5\%) $N=9$. The factors associated with HAND were older age OR: 1.06 (95\% Cl: 1.03, 1.10), male gender OR: 0.48 (95\% Cl: 0.24, 0.97), Advanced WHO clinical staging OR: $2.45(95 \% \mathrm{Cl}: 1.20,5.01)$ and a higher level of education; secondary/tertiary OR: 0.16 (95\% Cl: 0.07, 0.38); 0.11 (95\% Cl: 0.04, 0.35).

Conclusion: The prevalence of HAND in this study population was found to be high (81.1\%). Older age and advanced WHO clinical staging were associated with an increased risk of hand while higher level of education and male gender were protective.

Keywords: HIV-associated neurocognitive disorder (HAND), HIV-associated dementia (HAD), Sub-Saharan Africa (SSA)

\footnotetext{
* Correspondence: amy05nah@gmail.com

'Department of Medicine, Moi University School of Medicine, P.O. Box 4606-30100, Eldoret, Kenya

Full list of author information is available at the end of the article
}

(C) The Author(s). 2020 Open Access This article is licensed under a Creative Commons Attribution 4.0 International License, which permits use, sharing, adaptation, distribution and reproduction in any medium or format, as long as you give appropriate credit to the original author(s) and the source, provide a link to the Creative Commons licence, and indicate if changes were made. The images or other third party material in this article are included in the article's Creative Commons licence, unless indicated otherwise in a credit line to the material. If material is not included in the article's Creative Commons licence and your intended use is not permitted by statutory regulation or exceeds the permitted use, you will need to obtain permission directly from the copyright holder. To view a copy of this licence, visit http://creativecommons.org/licenses/by/4.0/ The Creative Commons Public Domain Dedication waiver (http://creativecommons.org/publicdomain/zero/1.0/) applies to the data made available in this article, unless otherwise stated in a credit line to the data. 


\section{Background}

HIV virus has a direct effect on the cellular immune system through depletion of infected CD4 lymphocytes and also has broad effects on the nervous system, including evidence for direct pathology in the brain, spinal cord, and peripheral nerves [1]. Neurological involvement of HIV remains an important problem since antiretroviral therapy (ART) has not fully accomplished full protection of the nervous system.

HIV-Associated Neurocognitive Disorders (HAND) are neurological disorders associated with HIV infection and AIDS. They have a highly variable clinical course and a spectrum of signs and symptoms, ranging from subtle cognitive and motor impairments to profound dementia [2].

A consensus research definition of HIV-associated neurocognitive disorder includes the sub classifications of: Asymptomatic Neurocognitive Impairment (ANI), HIV-associated Mild Neurocognitive Disorder (MND), and HIV-Associated Dementia (HAD) [3].

HAND even in its mild form is associated with less ability to perform the most complex daily tasks, worse quality of life, difficulty obtaining employment, and shorter survival [4]. In the study of individuals with longstanding aviremia, an overall prevalence of cognitive complaints was found to be $27 \%$. The prevalence of HAND was $84 \%$ among patients with cognitive complaints and $64 \%$ in those without. ANI was present in $24 \%$, MND in $52 \%$, and HAD in $8 \%$ [5].

HAND confers an increased risk for early mortality, independent of medical predictors $[6,7]$ and often interferes significantly with cognitively demanding activities of daily living such as employment, medication management and driving [8-10].

The gold standard for assessment of HAND is a detailed battery of neuropsychological tests, however; they are seldom available to patients in busy settings $[3,11]$. Various tools have been developed to help assess the neurocognitive dysfunction. Given the scarcity of the neuropsychological battery of tests, the screening tools such as the Montreal cognitive assessment (MoCA) and the International HIV dementia scale (IHDS) have been utilized in several studies in Sub Saharan Africa (SSA) including Kenya. These include the Montreal cognitive assessment (MoCA), which is more sensitive to the milder forms of HAND (ANI/MND) and the International HIV dementia scale (IHDS), which is more sensitive to the severe form of HAND (HAD). The Lawton Instrumental activity of daily living (IADL) has been used to assess the functional status of the patients, which are mostly impaired in patients diagnosed with HAND.

Despite HAND being an important cause of morbidity and mortality among people with HIV, its prevalence and the associated factors have not been well characterized in our set up.
A modified version of IHDS, the HIV Dementia Diagnostic Test, (by adding neurological and functional status items) was evaluated by Kwasa et al. in Kenya [12]. The modified tool exhibited moderate sensitivity and specificity of 63 and $67 \%$ respectively. A study aimed to define the performance characteristics of the IHDS in three East African countries (Kenya, Uganda, Tanzania), using the customary IHDS cut-off of 10, found a sensitivity of $91 \%$ with a specificity of $17 \%$ [13]. Sacktor et al. validated IHDS in Uganda with a cut off of $\leq 10$ for detection of HIV Dementia [14]. The sensitivity was $80 \%$ and specificity was $55 \%$. Kiswahili version of the MoCA (K-MoCA, has been recently validated in Tanzania [15] yielding a sensitivity of $70 \%$ and a specificity of $60 \%$ for Mild Cognitive Impairment, and sensitivity of $72 \%$ and specificity of $60 \%$ for dementia.

The three East African states have close socio-cultural practices and speak a common Swahili language. Therefore, the tools were used in the study, as the results of the tool validation may not differ significantly.

\section{Methods}

\section{Study aim, design and setting}

A cross-sectional analytical study conducted at Moi Teaching and Referral Hospital (MTRH) to determine the prevalence and the factors associated with HAND.

Adult HIV infected patients on ART were enrolled into care in the AMPATH (Academic Model Providing access to Healthcare) clinic at MTRH. AMPATH currently has more than 80,000 patients on ART. MTRH serves as the teaching hospital for Moi University School of Medicine and is the second largest tertiary referral centre in Kenya. It serves a population of 16 million people (40\% of Kenya's population) in western Kenya and is the primary care site for the 300,000 urban populations in Eldoret town.

Inclusion criteria included being HIV infected on ART and age between 18 years and 65 years. The exclusion criteria included active or known CNS opportunistic infection, fever of $>38^{\circ} \mathrm{C}$, history of chronic neurological disorder such as stroke, epilepsy and traumatic brain injury, active psychiatric disorder (presence of delusions, hallucinations and disorganized speech, catatonic behavior during the study evaluation and history of psychiatric disorder actively scrutinized in the medical records and the study questionnaire - Additional file 1), Alcoholism (CAGE score $>2$ ) and drug abuse, severe medical illness that would interfere with the ability to perform the study evaluation (Fig. 1).

\section{Sample size calculation and sampling technique}

Sample size of 360 patients was derived from fishers' exact formula.

The Sample size is calculated as shown below: 


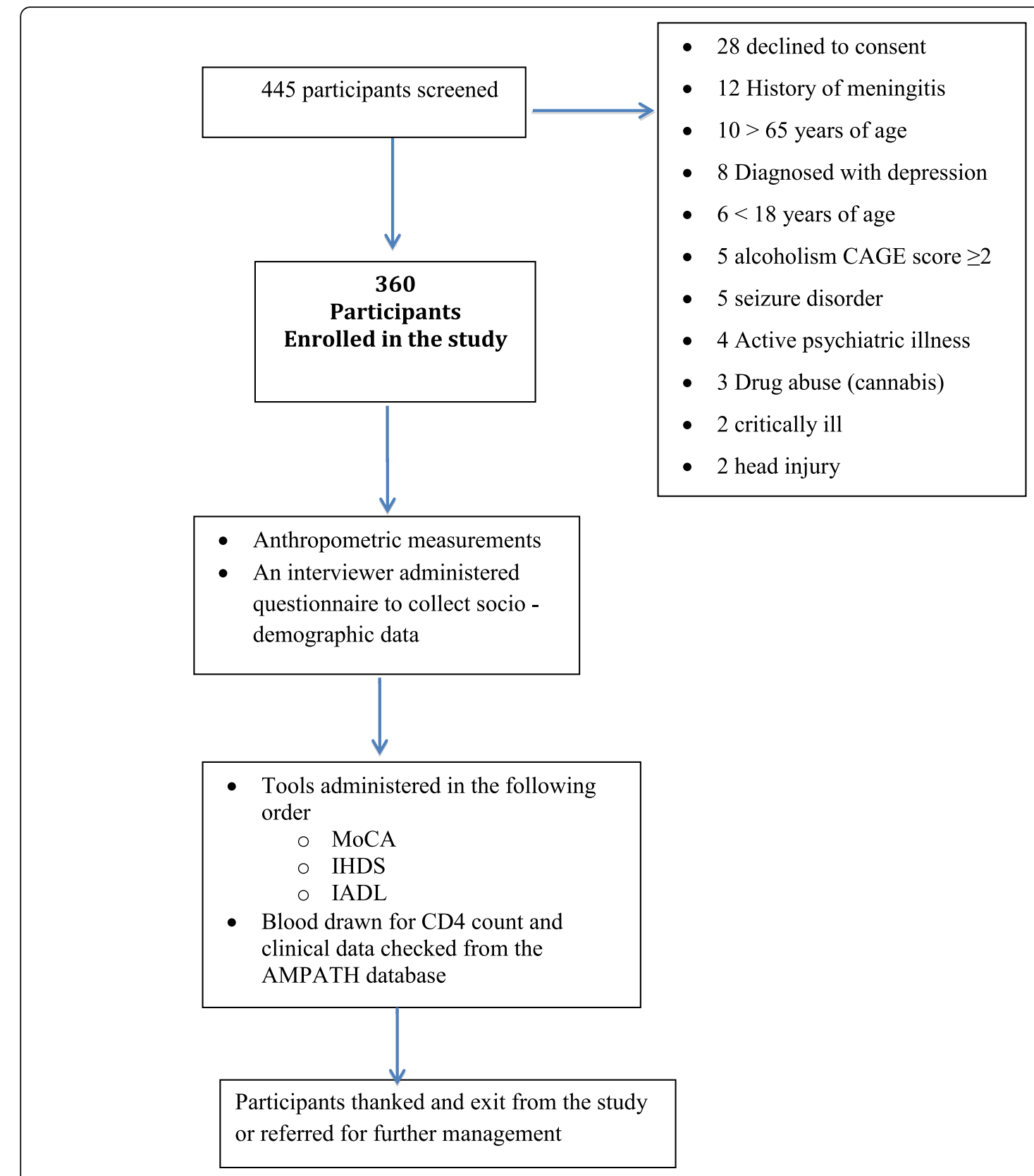

Fig. 1 Recruitment schema and study procedure

$$
\mathrm{N}=\frac{(\mathrm{Z} \alpha / 2)^{2} \times \mathrm{p}(1-\mathrm{p})}{\mathrm{d}^{2}}
$$

Where:

$\mathrm{N}=$ minimum sample size required $\alpha=$ the level of significance (5\%)

$\mathrm{Z} \alpha / 2=$ the value of $\mathrm{Z}$ at the selected level of significance

$\mathrm{p}=$ likely prevalence (31\%) - Ugandan studyN.Sacktor

$\mathrm{d}=P$ value $(0.05)$

$$
\mathrm{N}=\frac{\left(1.96^{2}\right) * 0.31 * 0.69}{(0.05)^{2}}
$$

$\mathrm{N}=328$ patients

$10 \%$ adjusted for non-response and missing data $=360$ patients

Systematic random sampling technique was used to sample the participants meeting the inclusion criteria. 
Data collection, variables and measurement

Participants had their anthropometric measurements: height and body weight measured. They were then taken through the interviewer administered structured questionnaire (Additional file 1) then the tools starting with the MoCA, IHDS then the IADL were administered by a well trained Psychologist who graduated with a Bachelor's degree from Moi University administered the screening tools. Subsequently, they were sent for the CD4 count at the AMPATH reference lab and the baseline CD4 count and viral load collected from the Academic Model Providing Access to Healthcare (AMPA $\mathrm{TH}$ ) database (Fig. 1).

The primary outcome variables definition: Asymptomatic neurocognitive impairment (ANI) - Based on low scores $<26$ in MoCA (Montreal cognitive assessment tool) and good performance in IHDS (International HIV dementia scale tool) $\geq 10$ and IADL score of 8 .

Mild neurocognitive disorder (MND) - Based on low scores < 26 in MoCA (Montreal cognitive assessment tool) and good performance in IHDS (International HIV dementia scale tool) $\geq 10$ and IADL score of $<8$.

HIV- Associated Dementia (HAD) - Based on low scores $<26$ in MoCA (Montreal cognitive assessment tool) and poor performance in IHDS (International HIV dementia scale tool) $<10$ and IADL score of $<8$.

The data variables collected included: age, gender, Body mass Index (BMI), level of income, level of education, WHO clinical staging, CD4 count, viral load, duration of HIV (Length of time since diagnosis), duration of HAART, type of ARV'S, Central penetration effectiveness (CPE) score and co-morbidities.

\section{Statistical analysis}

Data analysis was done using STATA. Descriptive statistics for measures of central tendency such as the mean and median were used to summarize continuous variables. The mean and the corresponding standard deviation were used to summarize continuous variables that assumed the Gaussian distribution. Such variables include age and years of education among others. Variables such as CD4, body mass index (BMI), duration of living with HIV, and duration of using HAART among others violated the Gaussian assumptions hence were summarized using the median and the corresponding inter quartile range (IQR). Gaussian assumptions were assessed using Shapiro-Wilk test and histograms. Frequencies and the corresponding percentages were used to summarize categorical variables such as gender, marital status, and education level, WHO clinical stage among others.

Pearson's Chi Square test was used to compare proportions between the participants diagnosed with HAND and those without HAND while Independent samples t- test was used to compare continuous variables between the participants diagnosed with HAND and those without HAND.

Logistic regression model was used to assess the determinants of HAND. Odds ratios (OR) and the corresponding 95\% confidence intervals $(95 \%$ CI $)$ were reported.

\section{Results}

\section{Socio-demographic and clinical characteristics}

A total of 360 participants with mean age 40.2 (SD: 11.5) years, Range: $18.0-65.0$ years were included in the study (Table 1).

The median BMI was 22.9 (IQR: 20.3, 25.5) $\mathrm{kg} / \mathrm{m}^{2}$ with $29.2 \%$ who were overweight or obese. Twenty-eight $(7.8 \%)$ of the participants had comorbidities. Hypertension was the predominant comorbidity affecting $6.3 \%$ of the total participants (Table 2).

The median baseline and current CD4 were 243.0 (10.8.0, 399.0) cells per $\mathrm{mm}^{3}$ and 491.0 (336.5, 701.0) cells per $\mathrm{mm}^{3}$ respectively. Fifty (16.4\%), and $48.3 \%$ had at least 500 cells per $\mathrm{mm}^{3}$ at baseline CD4 and current CD4 respectively. Three hundred and three $(84.6 \%)$ of

Table 1 Socio-demographic characteristics

\begin{tabular}{|c|c|c|}
\hline Variable & $\mathbf{N}$ & Mean (SD) or $n(\%)$ \\
\hline Age (Years) & 360 & $40.2(11.5)$ \\
\hline Range (Min. - Max.) & & $18.0-65.0$ \\
\hline Male & 360 & $126(35.0 \%)$ \\
\hline \multicolumn{3}{|l|}{ Marital status } \\
\hline Single & & $89(24.9 \%)$ \\
\hline Married & 358 & $161(45.0 \%)$ \\
\hline Divorced/Separated & & $38(10.6 \%)$ \\
\hline Widowed & & $70(19.6 \%)$ \\
\hline \multicolumn{3}{|l|}{ Education level } \\
\hline Primary & & $159(44.2 \%)$ \\
\hline Secondary & 360 & $155(43.1 \%)$ \\
\hline Tertiary & & $46(12.8 \%)$ \\
\hline Years of education & 360 & $9.9(3.1)$ \\
\hline Range (Min. - Max.) & & $2.0-18.0$ \\
\hline \multicolumn{3}{|l|}{ Occupation } \\
\hline Employed & & $82(22.8 \%)$ \\
\hline Self employed & 359 & $89(24.8 \%)$ \\
\hline Unemployed & & $188(52.4 \%)$ \\
\hline \multicolumn{3}{|c|}{ Level of income (Kenya Shillings/Month) } \\
\hline$<10000$ & & $302(86.5 \%)$ \\
\hline $10000-50000$ & 349 & $41(11.8 \%)$ \\
\hline $50000-100000$ & & $5(1.4 \%)$ \\
\hline$>100000$ & & $1(0.3 \%)$ \\
\hline
\end{tabular}

SD Standard Deviation 
Table 2 Clinical characteristics

\begin{tabular}{lll}
\hline Variable & $\mathbf{N}$ & Median (IQR) or $\mathbf{n}(\%)$ \\
\hline $\begin{array}{ll}\text { Body Mass Index }\left(\mathrm{Kg} / \mathrm{m}^{2}\right) \\
\quad 360\end{array}$ & $22.9(20.3,25.5)$ \\
$\quad$ Range (Min. - Max.) & & $14.8-54.0$ \\
$<18.5$ & $34(9.4 \%)$ \\
$18.5-25.0$ & 360 & $221(61.4 \%)$ \\
$25.0-30.0$ & & $86(23.9 \%)$ \\
$>30.0$ & & $19(5.3 \%)$ \\
Have comorbidities & 360 & $28(7.8 \%)$ \\
Comorbidities & & \\
Asthma & & $1(3.6 \%)$ \\
Diabetes mellitus & & $1(3.6 \%)$ \\
Hypertension & 28 & $23(82.1 \%)$ \\
Hypertension / Diabetes mellitus & & $2(7.1 \%)$ \\
Rheumatic Heart disease & & $1(3.6 \%)$ \\
\hline
\end{tabular}

IQR Inter Quartile Range

the participants had suppressed viral load and 160 (46.7\%) were in WHO clinical stages 3 or 4 (Table 3 ).

\section{Prevalence of HIV-associated neurocognitive disorder}

Based on MoCA 292 (81.1\%) of the participants had mild HAND, and 68 (18.9\%) were normal. Using IHDS, $9(2.5 \%)$ of the participants had severe HAND. There were 13 (3.6\%) who had functional impairment.

Diagnosis of HAND using the operational definitions demonstrated that $9(2.5 \%)$ had severe HAND, 283 (78.6\%) had mild HAND, and 68 (18.9\%) were normal (Table 4).

The participants diagnosed with HAND performed consistently and significantly worse than the cognitively normal group across all domains, except for the domain of orientation (Table 5).

\section{Association between socio-demographic characteristics and diagnosis of HAND}

Participants who were diagnosed with HAND were significantly older than those without HAND; 41.9 (SD: 10.6 ) vs. 33.0 (SD: 12.5 ) years, $p<0.001$. This demonstrates a $7 \%$ increased chance/risk of diagnosis of HAND among the older participants compared to the younger; OR: 1.07 (95\% CI: 1.05, 1.10).

Significantly lower proportion of male participants, and significantly higher proportion of the married participants were diagnosed with HAND compared to those without HAND; $32.5 \%$ vs. $45.6 \%, p=0.042$, and $47.6 \%$ vs. $33.8 \%, p=0.040$ respectively. These findings show that there was a $42 \%$ reduced odds of diagnosis of HAND among the male participants compared to the female, OR: 0.58 (95\% CI: 0.34, 0.98) and a 78\% increased odds of diagnosis of HAND among the married
Table 3 HIV treatment and markers of immunity

\begin{tabular}{|c|c|c|}
\hline Variable & $\mathbf{N}$ & Median (IQR) or $\mathrm{n}(\%)$ \\
\hline Duration since diagnosis of HIV (Months) & 360 & $107.0(71.5,132.0)$ \\
\hline Range (Min. - Max.) & & $1.0-181.0$ \\
\hline Duration before ART initiation (Months) & 360 & $44.0(4.5,78.5)$ \\
\hline Range (Min. - Max.) & & $0.0-166.0$ \\
\hline Duration of ART use (Months) & 360 & $88.0(51.0,122.5)$ \\
\hline Range (Min. - Max.) & & $1.0-141.0$ \\
\hline Duration of current ART (Months) & 360 & $51.0(17.0,76.0)$ \\
\hline Range (Min. - Max.) & & $0.0-147.0$ \\
\hline \multicolumn{3}{|l|}{ ART Line } \\
\hline First line (NRTI + NNRTI) & 360 & $286(79.4 \%)$ \\
\hline Second line (NRTI + PI) & & $74(20.6 \%)$ \\
\hline \multicolumn{3}{|l|}{ Others } \\
\hline Dapsone & & $5(1.4 \%)$ \\
\hline Septrin & 359 & $353(98.3 \%)$ \\
\hline Septrin/Isoniazid & & $1(0.3 \%)$ \\
\hline Suppressed viral load (< 1000 copies/ml) & 358 & $303(84.6 \%)$ \\
\hline Baseline CD4 cell count per $\mathrm{mm}^{3}$ & 304 & $243.0(10.8 .0,399.0)$ \\
\hline Range (Min. - Max.) & & $1.0-1459.0$ \\
\hline$<200.0$ & & $122(40.1 \%)$ \\
\hline $200.0-499.0$ & 304 & $132(43.4 \%)$ \\
\hline$\geq 500.0$ & & $50(16.4 \%)$ \\
\hline Current CD4 cell count per $\mathrm{mm}^{3}$ & 360 & $491.0(336.5,701.0)$ \\
\hline Range (Min. - Max.) & & $1.0-1845.0$ \\
\hline$<200.0$ & & $33(9.2 \%)$ \\
\hline $200.0-499.0$ & 360 & $153(42.5 \%)$ \\
\hline$\geq 500.0$ & & $174(48.3 \%)$ \\
\hline \multicolumn{3}{|l|}{ WHO Clinical stage } \\
\hline Stage 1 & & $122(35.6 \%)$ \\
\hline Stage 2 & 343 & $61(17.8 \%)$ \\
\hline Stage 3 & & $132(38.5 \%)$ \\
\hline Stage 4 & & $28(8.2 \%)$ \\
\hline
\end{tabular}

IQR Inter Quartile Range

$\mathrm{N}$ is less than 360 in other variables due to missing data

participants compared to the single/separated/widowed/ divorced, OR: 1.78 (95\% CI: 1.02, 3.09).

Compared to the participants without HAND, a significantly lower proportion of participants with secondary and tertiary level of education were diagnosed with HAND, $38.7 \%$ vs. $61.8 \%, p<0.001$, and $9.9 \%$ vs. $25.0 \%, p=0.001$ respectively. Compared to those with primary level of education, the participants with secondary and tertiary level of education had 84, and 90\% reduced odds of diagnosis of HAND; OR: 0.16 (95\% CI: 0.08, 0.35), and 0.10 (95\% CI: 0.04, 0.25) respectively (Table 6). 
Table 4 Montreal cognitive assessment (MoCA), International HIV dementia scale (IHDS), and the Lawton Instrumental Activities of Daily Living Scale (IADL)

\begin{tabular}{lll}
\hline Item & N & Mean (SD) or $\mathbf{n}(\%)$ \\
\hline MoCA & 360 & $21.2(4.2)$ \\
Range (Min. - Max.) & & $12.0-30.0$ \\
$\quad$ Mild ANI/MND (MoCA < 26) & 360 & $292(81.1 \%)$ \\
$\quad$ Normal (MoCA $\geq 26)$ & & $68(18.9 \%)$ \\
IHDS & 360 & $9.8(1.7)$ \\
Range (Min. - Max.) & & $5.0-12.0$ \\
$\quad$ HAD (IHDS < 10) & $9(2.5 \%)$ \\
$\quad$ No HAD (IHDS $\geq 10)$ & 360 & $351(97.5 \%)$ \\
IADL & 360 & $8.0(0.3)$ \\
Range (Min. - Max.) & & $5.0-8.0$ \\
Experienced functional impairment & 360 & $13(3.6 \%)$ \\
Activity & & \\
Food preparation/Housekeeping/Laundry & & $1(7.7 \%)$ \\
Food preparation/Laundry & 13 & $2(15.4 \%)$ \\
Responsibility for own medication & & $6(46.2 \%)$ \\
Laundry & & $3(23.1 \%)$ \\
Shopping & & $1(7.7 \%)$ \\
CPE score & 360 & $7.4(1.8)$ \\
Range (Min. - Max.) & $5.0-10.0$ \\
\hline SD Standd Devation &
\end{tabular}

SD Standard Deviation

\section{Association between clinical characteristics and diagnosis} of HAND

There was no evidence of a difference in BMI, baseline CD4 levels, current CD4 levels, WHO clinical stage, and presence of comorbidities between those who were diagnosed with HAND and those who did not have HAND, $p>0.05$.

The proportion of participants with suppressed viral load were similar for those who were diagnosed with HAND, and those who were normal, $85.5 \%$ vs. $80.9 \%$, $p=0.340$ respectively.

The average CPE score was significantly higher among those who were diagnosed with HAND compared to those without HAND; 7.6 (SD: 1.8) vs. 6.8 (SD: 1.7$), p<0.001$. The crude estimates show that the participants who had higher CPE score were associated with $30 \%$ increased odds of being diagnosed with HAND; OR: 1.30 (95\% CI: 1.11, 1.53) (Table 7).

\section{Logistic regression model assessing the determinants of diagnosis of HAND}

The level of income was retained in the model although it was not statistically significant. This is because income level confounded the effect of gender.

Years of current HAART, use of second line regimen, viral load suppression $(<1000$ copies $/ \mathrm{ml}$ ) and CPE score were retained despite them being not statistically significant since they clinically meaningful variables that are known to affect HAND.

Table 5 Comparison of Montreal cognitive assessment (MoCA), and International HIV dementia scale (IHDS) cognitive domains by presence or absence of HAND

\begin{tabular}{|c|c|c|c|c|}
\hline Domains & $\mathrm{N}$ & HAND $(N=292)$ & No HAND $(N=68)$ & $P$-value \\
\hline & & Mean (SD) & & \\
\hline \multicolumn{5}{|l|}{ MoCA } \\
\hline Executive & & $2.0(1.8)$ & $4.3(1.0)$ & $<0.001$ \\
\hline Naming & & $2.7(0.5)$ & $3.0(0.0)$ & $<0.001$ \\
\hline Attention & & $4.0(1.6)$ & $5.8(0.5)$ & $<0.001$ \\
\hline Language & & $1.1(0.6)$ & $1.8(0.7)$ & $<0.001$ \\
\hline Abstraction & & $1.0(0.6)$ & $1.5(0.6)$ & $<0.001$ \\
\hline Memory & & $2.4(1.8)$ & $4.3(1.0)$ & $<0.001$ \\
\hline Orientation & & $5.9(0.2)$ & $6.0(0.2)$ & 0.415 \\
\hline Total & & $19.8(3.4)$ & $27.0(1.0)$ & $<0.001$ \\
\hline \multicolumn{5}{|l|}{ IHDS } \\
\hline Motor speed & & $3.6(0.6)$ & $4.0(0.2)$ & $<0.001$ \\
\hline Psychomotor speed & & $3.0(0.7)$ & $3.7(0.5)$ & $<0.001$ \\
\hline Memory-recall & & $2.8(1.1)$ & $3.8(0.6)$ & $<0.001$ \\
\hline Total & & $9.4(1.6)$ & $11.5(0.9)$ & $<0.001$ \\
\hline
\end{tabular}

IHDS International HIV Dementia, MoCA Montreal Cognitive Assessment 
Table 6 Association between socio-demographic characteristics and diagnosis of HAND

\begin{tabular}{|c|c|c|c|c|}
\hline \multirow[t]{2}{*}{ Variable } & \multicolumn{2}{|l|}{ Presence of HAND } & \multirow[t]{2}{*}{$P$-value } & \multirow[t]{2}{*}{ UOR $(95 \% \mathrm{Cl})$} \\
\hline & $\begin{array}{l}\text { Yes }(n=292,81.1 \%) \\
\text { Mean (SD) or } n(\%)\end{array}$ & $\begin{array}{l}\text { No }(n=68,18.9 \%) \\
\text { Mean (SD) or } n(\%)\end{array}$ & & \\
\hline Age (Years) & $41.9(10.6)$ & $33.0(12.5)$ & $<0.001$ & $1.07(1.05,1.10)$ \\
\hline Male vs. Female & 95 (32.5\%) & $31(45.6 \%)$ & 0.042 & $0.58(0.34,0.98)$ \\
\hline Married vs. Single/Widowed/separated/divorced & $138(47.6 \%)$ & $23(33.8 \%)$ & 0.040 & $1.78(1.02,3.09)$ \\
\hline \multicolumn{5}{|l|}{ Education } \\
\hline Primary & $150(51.4 \%)$ & $9(13.2 \%)$ & $<0.001$ & Reference \\
\hline Secondary & $113(38.7 \%)$ & $42(61.8 \%)$ & 0.001 & $0.16(0.08,0.35)$ \\
\hline College & $29(9.9 \%)$ & $17(25.0 \%)$ & 0.001 & $0.10(0.04,0.25)$ \\
\hline \multicolumn{5}{|l|}{ Occupation } \\
\hline Unemployed & $153(52.6 \%)$ & $35(51.5 \%)$ & 0.869 & Reference \\
\hline Self employed & $71(24.4 \%)$ & $18(26.5 \%)$ & 0.722 & $0.90(0.48,1.70)$ \\
\hline Employed & $67(23.0 \%)$ & $15(22.1 \%)$ & 0.864 & $1.02(0.52,2.00)$ \\
\hline \multicolumn{5}{|l|}{ Income (Ksh.per Month) } \\
\hline$>10,000$ & 39 (13.6\%) & $8(12.7 \%)$ & & Reference \\
\hline$\leq 10,000$ & 247 (86.4\%) & 55 (87.3\%) & 0.843 & $0.92(0.41,2.08)$ \\
\hline
\end{tabular}

The findings demonstrate that older participants were associated with $6 \%$ increased odds of diagnosis of HAND compared to the younger participants, OR: 1.06 (95\% CI: $1.03,1.10)$ and male participants were associated with $52 \%$ reduced odds of being diagnosed with HAND, OR: 0.48 (95\% CI: 0.24, 0.97).

Education level was associated with diagnosis of HAND. The findings show that participants who had secondary level of education and those who had tertiary level of education were associated with 84 and $89 \%$ reduced odds of being diagnosed with HAND, OR: 0.16 (95\% CI: $0.07,0.38)$ and 0.11 (95\% CI: 0.04, 0.35) respectively.

Compared to low WHO clinical stage (stage 1 or 2), the advanced WHO clinical stage (stage 3 or 4 ) was associated with more than twice increased odds of being diagnosed with HAND, OR: 2.45 (95\% CI: 1.20, 5.01).

After adjusting for age, gender, education level, income, years on the current HAART, use of second line regimen, WHO clinical stage, and viral load level, the effect of CPE score was removed, AOR: 1.13 (95\% CI: $0.89,1.42$ ) (Table 8$)$.

\section{Discussion}

The prevalence of HAND in the study was $81.1 \%$. Mild HAND was $78.6 \%$ and severe HAND $2.5 \%$. The current literature depicts rising prevalence of the milder forms of HAND and decrease in severe form of HAND [16-18].

The screening tools for HIV-associated neurocognitive disorders among adults living with HIV in sub-Saharan Africa perform well in screening for severe forms of
HAND, but lack sensitivity and specificity for mild forms of HAND [19].

The overall prevalence is also higher compared to published literature but so far MoCA is the best tool for assessing mild neurocognitive impairment in the absence of new validated HAND screening tools in Sub-Saharan Africa. The 'gold standard' neuropsychological test battery is burdensome and rarely available in many African countries. To address this gap, many brief cognitive assessments have been developed and can be administered by trained personnel to identify the suspected cases among the high-risk population cohort for further formal diagnostic procedures.

Different viral clades may also account for the variation in HAND as certain clades maybe more or less neuropathogenic $[17,20,21]$. Neurocognitive deficit is more prevalent in regions where subtype C HIV predominates and this subtype is predominant in Sub- Saharan Africa. However, the viral clades were not studied in the present study.

Socio-demographic characteristics are important health features that affect the prevalence of HAND. Various studies on HAND in Africa included a relatively similar population with a mean age ranging from 29.75 to 40 years [22].

Older age was associated with HAND. This was similar to a study done in Zimbabwe [23], Thailand [24], and China [25]. This is thought to be due to the neurocognitive decline that comes with aging.

Men were less likely to have HAND. This was comparable to studies in Zambia [26] and Nigeria [27]. This is because of genetic and social factors. In the pathogenesis 
Table 7 Association between clinical characteristics and diagnosis of HAND

\begin{tabular}{|c|c|c|c|c|}
\hline \multirow[t]{2}{*}{ Variable } & \multicolumn{2}{|l|}{ Presence of HAND } & \multirow[t]{2}{*}{$P$-value } & \multirow[t]{2}{*}{ UOR $(95 \% \mathrm{Cl})$} \\
\hline & $\begin{array}{l}\text { Yes }(n=292,81.1 \%) \\
\text { Mean (SD) or } n(\%)\end{array}$ & $\begin{array}{l}\text { No }(n=68,18.9 \%) \\
\text { Mean (SD) or } n(\%)\end{array}$ & & \\
\hline \multicolumn{5}{|l|}{ BMI $\left(\mathrm{Kg} / \mathrm{m}^{2}\right)$} \\
\hline$<18.5$ & $24(8.2 \%)$ & $10(14.7 \%)$ & 0.099 & $0.56(0.25,1.27)$ \\
\hline $18.5-25.0$ & $179(61.3 \%)$ & $42(61.8 \%)$ & 0.944 & Reference \\
\hline $25.0-30.0$ & $73(25.0 \%)$ & $13(19.1 \%)$ & 0.306 & $1.32(0.67,2.60)$ \\
\hline$>30.0$ & $16(5.5 \%)$ & $3(4.4 \%)$ & 0.723 & $1.25(0.35,4.49)$ \\
\hline \multicolumn{5}{|l|}{ Baseline CD4 (cells per mm³) } \\
\hline$<200$ & $103(42.0 \%)$ & $19(32.2 \%)$ & 0.166 & Reference \\
\hline $200-500$ & $105(42.9 \%)$ & $27(45.8 \%)$ & 0.686 & $0.72(0.38,1.37)$ \\
\hline$>500$ & $37(15.1 \%)$ & $13(22.0 \%)$ & 0.197 & $0.53(0.24,1.17)$ \\
\hline \multicolumn{5}{|l|}{ Current CD4 (cells per mm³) } \\
\hline$<200$ & $27(9.3 \%)$ & $6(8.8 \%)$ & 0.913 & Reference \\
\hline $200-500$ & $121(41.4 \%)$ & $32(47.1 \%)$ & 0.398 & $0.84(0.32,2.21)$ \\
\hline$>500$ & $144(49.3 \%)$ & $30(44.1 \%)$ & 0.440 & $1.07(0.41,2.81)$ \\
\hline \multicolumn{5}{|l|}{ WHO Clinical stage } \\
\hline Stage 1 & 95 (34.4\%) & $27(40.3 \%)$ & 0.367 & Reference \\
\hline Stage 2 & 47 (17.0\%) & $14(20.9 \%)$ & 0.458 & $0.95(0.46,1.99)$ \\
\hline Stage 3 & $110(39.9 \%)$ & $22(32.8 \%)$ & 0.289 & $1.42(0.76,2.66)$ \\
\hline Stage 4 & $24(8.7 \%)$ & $4(6.0 \%)$ & 0.465 & $1.71(0.54,5.34)$ \\
\hline Have comorbidities & $23(7.9 \%)$ & $5(7.4 \%)$ & 0.879 & $1.08(0.40,2.96)$ \\
\hline \multicolumn{5}{|l|}{ Regimen } \\
\hline First line (NRTI + NNRTI) & $241(82.5 \%)$ & $45(66.2 \%)$ & & Reference \\
\hline Second line (NRTI + PI) & $51(17.5 \%)$ & $23(33.8 \%)$ & 0.003 & $0.41(0.23,0.74)$ \\
\hline Years on current HAART & $4.4(3.0)$ & $3.2(2.8)$ & 0.002 & $1.16(1.05,1.28)$ \\
\hline \multicolumn{5}{|l|}{ Individual HAART drugs } \\
\hline EFV/ETR/ABC & $139(47.6 \%)$ & 35 (51.5\%) & 0.565 & Reference \\
\hline AZT & $127(43.5 \%)$ & $18(26.5 \%)$ & 0.010 & $2.99(0.49,18.01)$ \\
\hline TDF & $161(55.1 \%)$ & $48(70.6 \%)$ & 0.020 & $1.93(0.33,11.15)$ \\
\hline NVP & $108(37.0 \%)$ & $12(17.7 \%)$ & 0.002 & $2.28(1.11,4.67)$ \\
\hline Years since HIV diagnosis & $8.1(3.7)$ & $8.4(3.7)$ & 0.620 & $0.98(0.91,1.06)$ \\
\hline Viral load < 1000 copies/ml & $248(85.5 \%)$ & 55 (80.9\%) & 0.340 & $1.40(0.70,2.77)$ \\
\hline CPE score & $7.6(1.8)$ & $6.8(1.7)$ & $<0.001$ & $1.30(1.11,1.53)$ \\
\hline
\end{tabular}

UOR Unadjusted Odds Ratio, 95\% Cl 95\% Confidence Interval

of HAND men have less immune activation of the macrophages, astrocytes and microglia hence less toxin signaling pathways that underlie the brain dysfunction in HAND. Most men in our African society are privileged to go to school and get educated while female play a role of doing house chores hence they have better cognitive reserve than women hence better cognitive performance [28].

Majority of the participants were married, unemployed with low level of income and this represents a low socioeconomic status of the patients. This was a predictor of poor neurocognitive performance as seen in a study in Cameroon [29].
Higher level of education was associated with less HAND. This was in line with findings from a systematic review in sub Saharan Africa [30], United States of America [16], and in South Africa [31]. Participants with higher level of education have better scoring in the screening tests, better awareness about the chronicity of HIV and good follow up resulting in good ART adherence and a reduced risk of HAND.

Assessment of the stage of HIV infection with WHO clinical staging, CD4 count and viral load is an important element in the evaluation of HAND. 
Table 8 Logistic regression model assessing the determinants of diagnosis of HAND

\begin{tabular}{|c|c|c|c|c|}
\hline \multirow[t]{2}{*}{ Variable } & \multicolumn{2}{|c|}{ Unadjusted Estimates } & \multicolumn{2}{|c|}{ Adjusted Estimates } \\
\hline & OR $(95 \% \mathrm{Cl})$ & $p$-value & OR $(95 \% \mathrm{Cl})$ & $p$-value \\
\hline Age (Years) & $1.07(1.05,1.10)$ & $<0.001$ & $1.06(1.03,1.10)$ & $<0.001$ \\
\hline Male & $0.58(0.34,0.98)$ & 0.042 & $0.48(0.24,0.97)$ & $<0.001$ \\
\hline \multicolumn{5}{|l|}{ Education level } \\
\hline Secondary vs. primary & $0.16(0.08,0.35)$ & 0.001 & $0.16(0.070 .38)$ & $<0.001$ \\
\hline Tertiary vs. Primary & $0.10(0.04,0.25)$ & 0.001 & $0.11(0.04,0.35)$ & $<0.001$ \\
\hline Income $\leq$ Ksh/Month10000 & $0.92(0.41,2.08)$ & 0.843 & $0.54(0.19,1.54)$ & 0.252 \\
\hline Years on current HAART & $1.16(1.05,1.28)$ & 0.002 & $1.04(0.90,1.19)$ & 0.627 \\
\hline On Second line regimen & $0.41(0.23,0.74)$ & 0.003 & $0.66(0.30,1.43)$ & 0.288 \\
\hline WHO stage $3 / 4$ vs. $1 / 2$ & $1.49(0.86,2.57)$ & 0.152 & $2.45(1.20,5.01)$ & 0.014 \\
\hline Viral load < 1000 copies/ml & $1.40(0.70,2.77)$ & 0.340 & $0.70(0.28,1.73)$ & 0.439 \\
\hline CPE score & $1.30(1.11,1.53)$ & $<0.001$ & $1.13(0.89,1.42)$ & 0.312 \\
\hline Sample Size & & & 331 & \\
\hline
\end{tabular}

OR Odds Ratio, $\mathrm{Cl}$ Confidence Interval

Majority of the participants were in WHO clinical stages 3 and 4 . Advanced WHO clinical stage 3 or 4 was associated with more than twice increased odds of being diagnosed with HAND. This was similar to other studies, which showed increased rate of HAND with advanced stages of HIV infection in Nigeria [32, 33], and in Uganda [34].

There is evidence of advanced immunosuppression leading to a higher incidence of HIV associated brain injury and also most patients present to the hospitals with late stage of HIV infection and advanced neurocognitive impairment.

Studies in the HAART era have shown that current CD4 counts have no correlation and are not predictive of HAND [35]. Current CD4 count was significant in the Pre HAART era. In the above study it did not appear as an important marker.

The baseline CD4 cell count informs the likelihood that progressive cognitive impairment is due to $\mathrm{HAD}$, which occurs at counts of $<200$ cells per $\mathrm{mm}^{3}$ in untreated patients. From the study, the Prevalence of HAD was very low and could explain the lack of association.

The proportion of participants with suppressed viral loads $<1000$ copies per $\mathrm{ml}$ were similar in both those with HAND and the normal participants. The findings were similar to others, which revealed that markers such as plasma viral load are not associated with HAND [4, 35-37].

This shows that normalization of immune indices that reflect peripheral immune function does not adequately reflect the environment that continues to exist in the CNS. CSF viral load has shown promise as a predictor of HAND but more studies need to establish the association.

In the study, CPE score was not associated with HAND after adjusting for the other variables. This was similar to findings by Marra et al. and Cysique et al. [38, 39].
The cross sectional study design limited meaningful interpretation of the relationship between CPE scores and the presence of HAND since the timing of treatment initiation and duration of treatment need to be considered. Besides, the national ART treatment guidelines determine the initial ART regimen choice and thereby the CPE scores.

\section{Study limitations}

Neuropsychological test battery is the gold standard for diagnosis of HAND; however the availability of these tests together with the expertise needed for their administration is limited in our set up. We therefore chose to use screening tools that have been validated locally (using neuropsychological test battery as gold standard) as surrogate diagnostic screening tests. These tests have moderate utility in diagnosing HAND but are easy to use in routine clinical practice and allows for comparison of our findings with previous studies that have used similar tools.

Finally, there are potential confounders, which we did not assess for as baseline such as the nadir CD4 cell count.

\section{Conclusion and recommendation}

The prevalence of HAND remains high in this HAART error with a higher prevalence of mild HAND (78.6\%) and low prevalence of severe HAND (2.5\%).

The independent factors associated with HAND are age, gender, level of education and WHO clinical stage.

Therefore there is need for early screening for HAND in HIV infected patients and a future prospective study to help understand the true association between HAND and the CPE score of ART regimen. 


\section{Supplementary information}

Supplementary information accompanies this paper at https://doi.org/10. 1186/s12883-020-01857-3.

Additional file 1. Study Questionnaire -Demographic Data.

\section{Abbreviations}

AMPATH: Academic Model Providing Access to Healthcare;

ANI: Asymptomatic Neurocognitive Impairment; ABC: Abacavir; ART: Antiretroviral therapy; ARV: Antiretroviral drugs; ATV-r: Atazanavir/ ritonavir; AZT: Zidovudine; BMI: Body Mass Index; CNS: Central Nervous System; CD4: Cluster of differentiation 4; CPE: Central nervous system Penetration Effectiveness; ETR: Etravirine; EFV: Efavirenz; HAD: HIV-Associated Dementia; HAND: HIV-Associated Neurocognitive Disorders; HAART: Highly Active Antiretroviral Therapy; IADL: Lawton Instrumental Activities of Daily Living; IHDS: International HIV Dementia Scale; LPV-r: Lopinavir/ ritonavir; MND: HIV-associated Mild Neurocognitive Disorder; MoCA: Montreal Cognitive Assessment tool; MTRH: Moi Teaching and Referral Hospital; NVP: Nevirapine; NRTI: Nucleoside reverse transcriptase inhibitors; NNRTI: Non-nucleoside reverse transcriptase inhibitors; PI: Protease Inhibitors; SSA: Sub Saharan Africa; TDF: Tenofovir; 3TC: Lamivudine

\section{Acknowledgements}

I would like to acknowledge everyone who played a role in the success of this manuscript. I would specifically like to appreciate the contribution of Benson Njuguna in the compilation process. The authors thank the Department of Medicine at Moi University, the Academic Model Providing Access to Healthcare (AMPATH) and the study participants for their support and co-operation.

\section{Authors' contributions}

AAM prepared the first draft of the manuscript. All authors (AAM, CO and DK) were involved in the conceptualization of this work, interpretation of study findings, substantive review of manuscript drafts, and approval of the final manuscript for submission.

\section{Funding}

The National Research Fund (NRF) in Kenya funded this study. The funding provided catered for the costs of laboratory work for assessment of CD4 count levels.

\section{Availability of data and materials}

The datasets used during the study are available from the corresponding author on reasonable request.

\section{Ethics approval and consent to participate}

The Moi University School of Medicine and Moi Teaching and Referral Hospital Institutional Research and Ethics Committee approved this study. Written informed consent was obtained from all the study participants.

\section{Consent for publication}

Not applicable.

\section{Competing interests}

The authors declare that they have no competing interest.

\section{Author details}

'Department of Medicine, Moi University School of Medicine, P.O. Box 4606-30100, Eldoret, Kenya. ${ }^{2}$ Department of Mental Health, Moi University School of Medicine, P.O. Box 4606-30100, Eldoret, Kenya.

\section{Received: 8 August 2019 Accepted: 7 July 2020}

\section{Published online: 14 July 2020}

\section{References}

1. Harrison MJG, M. J. AIDS and neurology. Edinburgh: Churchill Livingstone; 1995.

2. Clifford DB, Ances BM. HIV-associated neurocognitive disorder. Lancet Infect Dis. 2013;13(11):976-86.
3. Antinori A, Arendt G, Becker JT, Brew BJ, Byrd DA, Cherner M, Clifford DB, Cinque P, Epstein LG, Goodkin K, et al. Updated research nosology for HIVassociated neurocognitive disorders. Neurology. 2007;69(18):1789-99.

4. Simioni S, Cavassini M, Annoni JM, Rimbault Abraham A, Bourquin I, Schiffer V, Calmy A, Chave JP, Giacobini E, Hirschel B, et al. Cognitive dysfunction in HIV patients despite long-standing suppression of viremia. AIDS (London, England). 2010;24(9):1243-50.

5. McArthur JC, Brew BJ. HIV-associated neurocognitive disorders: is there a hidden epidemic? AIDS (London, England). 2010;24(9):1367-70.

6. Ellis HD, Jones DM, Mosdell N. Intra- and inter-modal repetition priming of familiar faces and voices. Br J Psychol (London, England: 1953). 1997;88(Pt 1):143-56.

7. Mayeux R, Stern Y, Ottman R, Tatemichi TK, Tang MX, Maestre G, Ngai C, Tycko B, Ginsberg $H$. The apolipoprotein epsilon 4 allele in patients with Alzheimer's disease. Ann Neurol. 1993:34(5):752-4.

8. Heaton RK, Franklin DR Jr, Deutsch R, Letendre S, Ellis RJ, Casaletto K, Marquine MJ, Woods SP, Vaida F, Atkinson JH, et al. Neurocognitive change in the era of HIV combination antiretroviral therapy: the longitudinal CHAR TER study. Clin Infect Dis. 2015;60(3):473-80.

9. Heaton RK, Marcotte TD, Mindt MR, Sadek J, Moore DJ, Bentley H, McCutchan JA, Reicks C, Grant I. The impact of HIV-associated neuropsychological impairment on everyday functioning. J Int Neuropsychol Soc. 2004;10(3):317-31.

10. Hinkin CH, Hardy DJ, Mason Kl, Castellon SA, Durvasula RS, Lam MN, Stefaniak M. Medication adherence in HIV-infected adults: effect of patient age, cognitive status, and substance abuse. AIDS (London, England). 2004; 18(Suppl 1):S19-25.

11. Folstein MF, Robins LN, Helzer JE. The mini-mental state examination. Arch Gen Psychiatry. 1983;40(7):812.

12. Kwasa J, Cettomai D, Lwanya E, Osiemo D, Oyaro P, Birbeck GL, Price RW, Bukusi EA, Cohen CR, Meyer A-CL. Lessons learned developing a diagnostic tool for HIV-associated dementia feasible to implement in resource-limited settings: pilot testing in Kenya. PLoS One. 2012;7(3):e32898.

13. Milanini B, Paul R, Bahemana E, Adamu Y, Kiweewa F, Langat R, Owuoth J, Allen E, Polyak C, Ake J, et al. Limitations of the International HIV Dementia Scale in the current era. AIDS (London, England). 2018;32(17):2477-83.

14. Sacktor NC, Wong M, Nakasujja N, Skolasky RL, Selnes OA, Musisi S, Robertson K, McArthur JC, Ronald A, Katabira E. The International HIV Dementia Scale: a new rapid screening test for HIV dementia. AIDS (London, England). 2005;19(13):1367-74.

15. Masika GM, Yu DSF, Li PWC. Accuracy of the Montreal Cognitive Assessment in Detecting Mild Cognitive Impairment and Dementia in the Rural African Population. Arch Clin Neuropsychol. 2020. https://doi.org/10.1093/arclin/ acz086.

16. Cross S, Onen N, Gase A, Overton ET, Ances BM. Identifying risk factors for HIV-associated neurocognitive disorders using the international HIV dementia scale. J Neurolmmune Pharmacol. 2013;8(5):1114-22.

17. Nabha L, Duong L, Timpone J. HIV-associated neurocognitive disorders: perspective on management strategies. Drugs. 2013;73(9):893-905.

18. Woods SP, Moore DJ, Weber E, Grant I. Cognitive neuropsychology of HIVassociated neurocognitive disorders. Neuropsychol Rev. 2009;19(2):152-68.

19. Mwangala PN, Newton CR, Abas M, Abubakar A. Screening tools for HIVassociated neurocognitive disorders among adults living with HIV in subSaharan Africa: a scoping review. AAS Open Res. 2019;1:28.

20. Lovejoy TI, Suhr JA. The relationship between neuropsychological functioning and HAART adherence in HIV-positive adults: a systematic review. J Behav Med. 2009;32(5):389-405.

21. Tedaldi EM, Minniti NL, Fischer T. HIV-associated neurocognitive disorders: the relationship of HIV infection with physical and social comorbidities. Biomed Res Int. 2015;2015:641913.

22. Habib AG, Yakasai AM, Owolabi LF, Ibrahim A, Habib ZG, Gudaji M, Karaye KM, Ibrahim DA, Nashabaru I. Neurocognitive impairment in HIV-1-infected adults in sub-Saharan Africa: a systematic review and meta-analysis. Int J Infect Dis. 2013;17(10):e820-31.

23. Chibanda D, Benjamin L, Weiss HA, Abas M. Mental, neurological, and substance use disorders in people living with HIV/AIDS in low- and middleincome countries. J Acquir Immune Defic Syndr (1999). 2014;67(Suppl 1): S54-67.

24. Heaps J, Valcour V, Chalermchai T, Paul R, Rattanamanee S, Siangphoe U, Sithinamsuwan P, Chairangsaris P, Nidhinandana S, Tipsuk S, et al. Development of normative neuropsychological performance in Thailand for 
the assessment of HIV-associated neurocognitive disorders. J Clin Exp Neuropsychol. 2013;35(1):1-8.

25. Zhang Y, Qiao L, Ding W, Wei F, Zhao Q, Wang X, Shi Y, Li N, Smith D, Chen D. An initial screening for HIV-associated neurocognitive disorders of HIV-1 infected patients in China. J Neuro-Oncol. 2012;18(2):120-6.

26. Hestad KA, Menon JA, Silalukey-Ngoma M, Franklin DR Jr, Imasiku ML, Kalima K, Heaton RK. Sex differences in neuropsychological performance as an effect of human immunodeficiency virus infection: a pilot study in Zambia, Africa. J Nerv Ment Dis. 2012;200(4):336-42.

27. Royal W 3rd, Cherner M, Burdo TH, Umlauf A, Letendre SL, Jumare J, Abimiku A, Alabi P, Alkali N, Bwala S, et al. Associations between cognition, gender and monocyte activation among HIV infected individuals in Nigeria. PLoS One. 2016;11(2):e0147182.

28. Kabuba N, Menon JA, Franklin DR Jr, Heaton RK, Hestad KA. HIV- and AIDSassociated neurocognitive functioning in Zambia - a perspective based on differences between the genders. Neuropsychiatr Dis Treat. 2016;12:2021-8.

29. Atashili J, Gaynes BN, Pence BW, Tayong G, Kats D, O'Donnell JK, Ndumbe PM, Njamnshi AK. Prevalence, characteristics and correlates of a positivedementia screen in patients on antiretroviral therapy in Bamenda, Cameroon: a cross-sectional study. BMC Neurol. 2013;13:86.

30. Breuer E, Myer L, Struthers H, Joska JA. HIV/AIDS and mental health research in sub-Saharan Africa: a systematic review. Afr J AIDS Res. 2011;10(2):101-22.

31. Joska JA, Fincham DS, Stein DJ, Paul RH, Seedat S. Clinical correlates of HIVassociated neurocognitive disorders in South Africa. AIDS Behav. 2010;14(2): $371-8$.

32. Odiase FE, Ogunrin OA, Ogunniyi AA. Memory performance in HIV/AIDS--a prospective case control study. Can J Neurol Sci. 2007;34(2):154-9.

33. Wong MH, Robertson K, Nakasuija N, Skolasky R, Musisi S, Katabira E, McArthur JC, Ronald A, Sacktor N. Frequency of and risk factors for HIV dementia in an HIV clinic in sub-Saharan Africa. Neurology. 2007;68(5):350-5.

34. Heaton RK, Grant I, Butters N, White DA, Kirson D, Atkinson JH, McCutchan JA, Taylor MJ, Kelly MD, Ellis RJ, et al. The HNRC 500--neuropsychology of HIV infection at different disease stages. HIV neurobehavioral research center. J Int Neuropsychol Soc. 1995;1(3):231-51.

35. Tozzi V, Balestra P, Bellagamba R, Corpolongo A, Salvatori MF, ViscoComandini U, Vlassi C, Giulianelli M, Galgani S, Antinori A, et al. Persistence of neuropsychologic deficits despite long-term highly active antiretroviral therapy in patients with HIV-related neurocognitive impairment: prevalence and risk factors. J Acquir Immune Defic Syndr (1999). 2007:45(2):174-82.

36. Brew BJ. Evidence for a change in AIDS dementia complex in the era of highly active antiretroviral therapy and the possibility of new forms of AIDS dementia complex. AIDS (London, England). 2004;18(Suppl 1):S75-8.

37. Brew BJ, Crowe SM, Landay A, Cysique LA, Guillemin G. Neurodegeneration and ageing in the HAART era. J Neurolmmune Pharmacol. 2009:4(2):163-74.

38. Cysique LA, Vaida F, Letendre S, Gibson S, Cherner M, Woods SP, McCutchan JA, Heaton RK, Ellis RJ. Dynamics of cognitive change in impaired HIV-positive patients initiating antiretroviral therapy. Neurology. 2009;73(5):342-8

39. Marra CM, Zhao Y, Clifford DB, Letendre S, Evans S, Henry K, Ellis RJ, Rodriguez B, Coombs RW, Schifitto G, et al. Impact of combination antiretroviral therapy on cerebrospinal fluid HIV RNA and neurocognitive performance. AIDS (London, England). 2009;23(11):1359-66.

\section{Publisher's Note}

Springer Nature remains neutral with regard to jurisdictional claims in published maps and institutional affiliations.

Ready to submit your research? Choose BMC and benefit from:
- fast, convenient online submission
- thorough peer review by experienced researchers in your field
- rapid publication on acceptance
- support for research data, including large and complex data types
- gold Open Access which fosters wider collaboration and increased citations
- maximum visibility for your research: over 100M website views per year
At BMC, research is always in progress.
Learn more biomedcentral.com/submissions

